\title{
RACIONALIDAD MORAL Y JUSTICIA SOCIAL DE LAS INSTITUCIONES POLIITICAS*
}

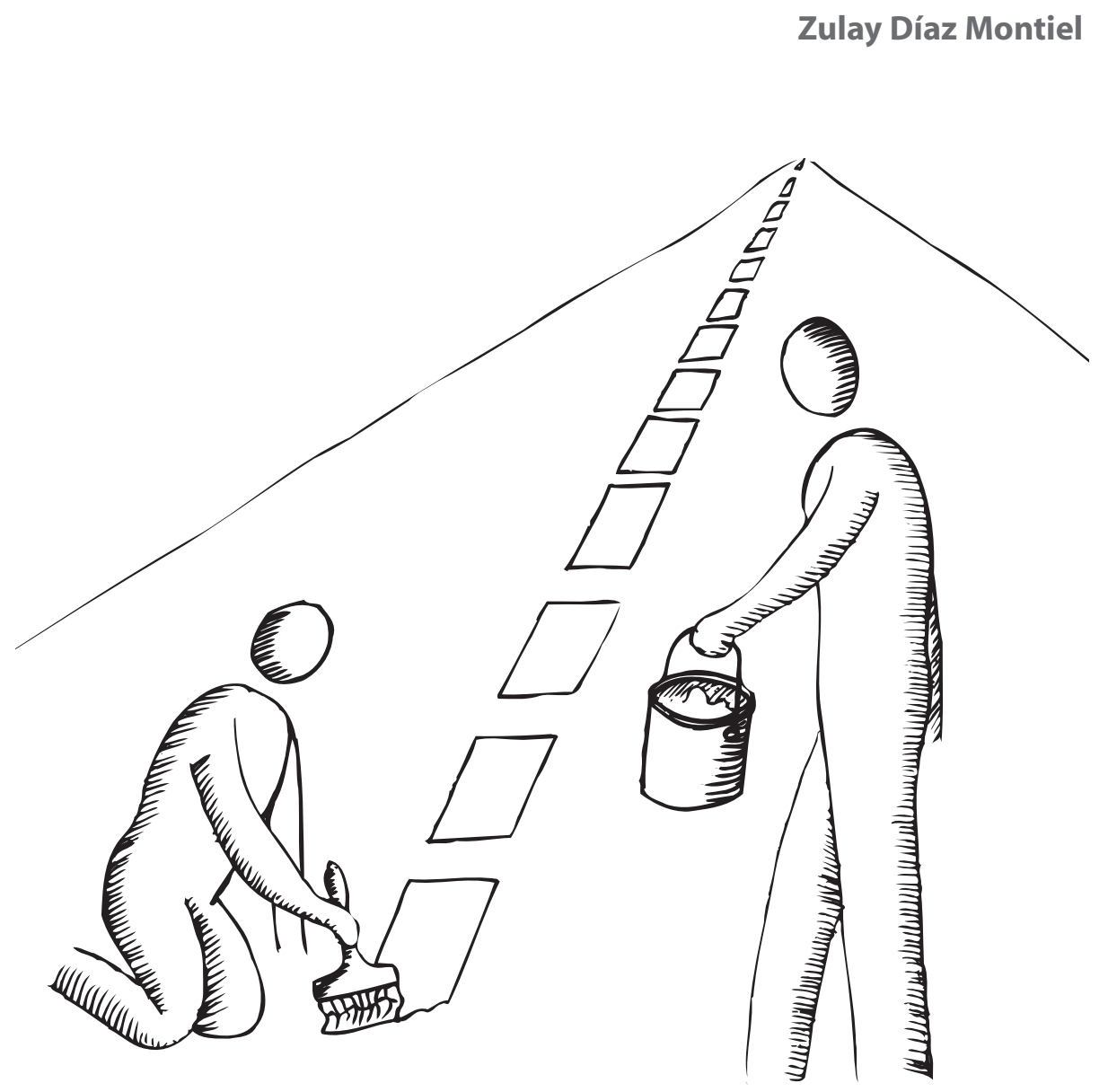

* Este artículo es un resultado parcial del proyecto de investigación No. 2 intitulado:"Racionalización social en la razón instrumental de las instituciones políticas", adscrito al Programa de Investigación: INTERCULTURALIDAD Y RAZÓN EPISTÉMICA EN AMÉRICA LATINA, inserto en la Línea de Investigación: Estudios Epistemológicos y Metodológicos de las Ciencias Sociales del Centro de Estudios Sociológicos y Antropológicos (CESA) de la Facultad de Ciencias Económicas Y Sociales de la Universidad del Zulia, y cofinanciado por el Consejo de Desarrollo Científico Y Humanístico. 


\section{Zulay Díaz Montiel}

\section{Resumen}

En este artículo se analizan algunos aspectos básicos del proceso emancipatorio que debe surgir en la sociedad contemporánea, desde el punto de vista de la moralidad pública y la justicia social de sus instituciones políticas. Se opone a la racionalidad instrumental del derecho positivo de la modernidad, los principios y razones morales de la política según el planteamiento comunicativo, discursivo e intersubjetivo de Jürgen Habermas. El resultado es interesante: no es posible el ejercicio de la política sin moral; mas todavía, no es realizable la justicia sin un proyecto liberador compartido. Desde esta perspectiva se busca interpretar el sentido de integración social que cumple la pragmática comunicativa, el diálogo y el espacio público.

Racionalidad moral y justicia social de las instituciones políticas, en la reconstrucción de las instituciones socio-políticas. Moral y justicia son dos instancias que deben configurar el rostro político del Estado, y los proyectos que demanda la ciudadanía para ampliar la democracia participativa nos proponen un examen de la crisis del Estado moderno.

Palabras clave: racionalidad, moralidad, instituciones, justicia emancipadora.
Moral Rationality and Social Justice in Political Institutions

This article analyzes some basic aspects of the emancipatory process that should arise in contemporary society, from the viewpoint of the public morality and social justice of its political institutions. It opposes the instrumental rationality of modern positive law, the principles and moral reasons of politics according to the communicative, discursive and inter-subjective approach of Habermas. The result is interesting: it is not possible to exercise politics without morality; moreover, justice cannot be achieved without a shared liberating project. From this perspective, the study seeks to interpret the sense of social integration that the communicative pragmatic, dialogue and the public space fulfill in the reconstruction of s6cio-political institutions. Morality and justice are two applications that ought to configure the political face of the State, and the projects demanded by the citizenry to broaden participative democracy propose an examination of the crisis of the modern State.

Key words: Rationality, morality, institution, emancipating justice.

\section{Introducción}

En las sociedades actuales se vuelve necesario oponer a la racionalidad 
estratégica institucionalizada del Estado postcapitalista, una racionalidad práctica y dialógica suficiente, que permita cuestionar y responder con razones morales a los principios tecnocientistas en los que se fundan las formas y contenido de la política moderna. Se trata entonces de poder reconstruir el mundo objetivo desde las libertades subjetivas que se gestan y reconocen entre los actores sociales, a partir de una intersubjetividad de vidas compartidas. En tal sentido, el programa de dialogizar la política, más que recurrir a los dominios técnicos del quehacer político, intenta alcanzar niveles de justicia social que en su práctica constituyente respondan a las acciones e intereses de la mayoría social. Deben originarse relaciones sociopolíticas que puedan ser abordadas desde una racionalidad comunicativa, donde consensuar y discernir, sean los fines en sí mismos de esas prácticas políticas a las que todos tienen derecho.

Pero para lograr que esos fines mancomunados, en los que el "todos” es sinónimo de una mayoría incluyente, puedan contener y debidamente representar a unos y otros, es preciso que las lógicas de la racionalidad de las instituciones políticas de la modernidad, puedan ser transformadas en estructuras de interac- ción social menos deterministas y más plurales. Es decir, se trata de refundar el proyecto político del Estado moderno por medio de una discusión democrática de los fines de su institucionalidad social, económica y científica, y para eso es imprescindible interpelar el ámbito de la moral pública del Estado y las responsabilidades éticas de su gestión de gobierno.

Los cambios sociales que solicita la ciudadanía, en su diversidad y heterogeneidad ideológica o de clases, deben ser interpretados en el escenario institucional y político en los que estos ciudadanos actúan. Más allá de los partidos políticos y los aparatos de poder del Estado; hoy día las sociedades de la modernidad capitalista se enfrentan al fenómeno de mayores demandas de participación directa y cogestión negociada, entre los intereses particulares de los ciudadanos y aquellos generales que se les proponían como colectivo social. La dirección política y económica de la sociedad, no puede seguir formando parte del dominio estratégico y funcional de las "instituciones sociales" que le sirven de contexto legitimador al Estado.

Hoy en día, y cada vez más, la presencia del Estado no es omnipresente, por el contrario, debe pasar por 


\section{Zulay Díaz Montiel}

un sistema de relaciones e interacciones sociales que tienda a la construcción de conductas y discursos acerca de lo que es la política, donde el Estado y la ciudadanía, se ven en la obligada necesidad de dialogar sobre aquellos medios y fines que deben poner en práctica para el logro de bienes comunes a partir de la diversidad de intereses que pueden ser afines con todos los involucrados. La nueva sociedad política debería resultar de un diálogo donde la ciudadanía pueda ser en efecto, emiso$\mathrm{ra} /$ receptora y viceversa, del poder de las prácticas políticas; es decir, de ese poder constituyente, que por vía de la participación y coparticipación logre fundar normas morales que puedan ser reconocidas como validas por esta, lo que haría posible, otro modo de razonar la política ya que desaparecerían las fuerzas coactivas del Estado y aparecerían las fuerzas comunicativas y argumentativas de la Sociedad Civil, en busca de una eticidad donde lo público funcionaría como el escenario de reconocimiento de ese "todos" del que forma parte el colectivo social y que dejaría de ser una abstracción.

La sociedad se convierte así, en un proyecto de vida para todos, capaz de responder y resolver la conflictividad que ha caracterizado a la sociedad de clases en la que ha reposado el Estado moderno. Una sociedad emancipada de estructuras de dominio y control político será una mucho más abierta a la deliberación, al disenso, a la tolerancia y a la justicia; capaz de contrastar y arbitrar los intereses individuales con los generalizables, al querer fundamentar éstos en decisiones morales que sean tratadas desde un espacio público donde se los discuta y practique.

\section{Sociedad, Estado, ciudada- nía y moralidad pública}

Las relaciones sociales que desarrolla el Estado se transforman estructuralmente, en un primer momento, a causa de las propias instituciones que le sirven de justificación y reproducción; sin embargo, esto no siempre es suficiente para que la sociedad y el Estado, en esa relación de conjunto y complemento que le garantiza su existencia, se desarrollen históricamente. La relación normativa entre Estado y sociedad, no supone siempre una relación simétrica que excluya la discordia, la violencia y el conflicto. Esto no es así, precisamente, porque en un segundo momento, la relación está dinamizada por la intervención que hacen los actores -no entes abstractos- de ambos espacios, desde una relación de fuerza que tiene su corresponden- 
cia con el interés del control político que se desea ejecutar sobre la sociedad y sobre el Estado. Estas dos esferas se complementan y se median entre sí, en razón de la concepción y la praxis política que sus actores despliegan: se acercan o distancian y se aproximan o alejan, en relación a su concepto de poder político. Y para lograr una particular (individual) o general (colectiva) hegemonía de esa relación entre sociedad y Estado, los actores se presentan en un espacio público donde se ven en la necesidad de asumir y defender sus identidades sociales.

Entonces, este es el lugar donde la política queda asociada a diversas formas de racionalidad con las que se debate el sentido que se le debe asignar a las prácticas políticas y sus respectivos fines. La mediación e intersección que se abre entre Sociedad Civil y sociedad política, a partir de este segundo momento de desarrollo de la interacción entre ambas esferas, es de carácter eminentemente discursivo y dialógico, pues, no puede entenderse de otra manera en su origen y destino, la actuación de los ciudadanos en el espacio público donde -entre todos- se construye e instituye el orden de la política, y sólo mediante el lenguaje, el discurso, el argumento, la crítica y la opinión, es que se hace pública la interacción entre los actores, vale decir, entre los ciudadanos.

Intervenir dialógica y comunicativamente en política supone interactuar socialmente a través de los diversos espacios públicos en los que se desarrollan los poderes y las instituciones públicas del Estado. Para que eso sea posible, es necesario que se establezcan y reconozcan normas, códigos, leyes, derechos, que permitan una participación en igualdad de condiciones, democráticamente abierta a la interacción política -es decir, a la capacidad de intervenir sobre el orden de la sociedad y la estructura del Estado- de cualquiera que también constituya parte de la sociedad, y que en ciertos momentos o épocas, pudieran quedar fuera del sistema.

En este nuevo siglo, que se abre a relaciones sociales y políticas discontinuas fuertemente tratadas desde la multiculturalidad, los aportes de la Teoría de la Acción Comunicativa, de Habermas, permiten generar una crítica a los modelos positivistas de la sociedad y del Estado, pero de igual manera, buscan destacar el imperativo de definir y evaluar las tesis pragmáticas que le sirven de apoyo para interpretar a la sociedad desde la teoría del lenguaje y de la comunicación, la moralidad y la eticidad. 


\section{Zulay Díaz Montiel}

Estos son parámetros que nos pueden guiar en la búsqueda de respuestas acordes con los nuevos roles sociales y proyectos de identidades ciudadanas, mucho más democráticos y plurales. Lograrlo es proponer, dentro de un contexto sociopolítico, la apertura hacia un nuevo paradigma de la vida social y del Estado, donde sea viable desarrollar las intersubjetividades que hacen posible, comprender y poner en acción, procesos a través de los cuales el actual dominio técnico de la política sobre lo público, pueda ser efectivamente superado.

Es indiscutible que la institucionalidad le aporta a la estructura social un sentido que no puede ser únicamente formal y abstracto (Castoriadis, 2001). Las instituciones, representan procesos y hechos sociales en los que todos debemos estar contenidos según consensos compartidos desde argumentos válidos para todos; lo contrario supondría que los hechos son consecuencias de acciones sin una racionalidad que los dirija. Si se pierde el sentido social que debe tener lo que es socialmente humano en nuestra condición de seres vivos; entonces, se pierde nuestra capacidad para ser libres y para convivir dentro de principios de justicia material y derechos humanos.
En este orden de ideas, es imprescindible comenzar a entender que el desarrollo de las sociedades responde a la interacción ciudadana que se genera en el espacio público que le sirve de contextualidad; pero también, que el desarrollo orgánico del Estado, desde el punto de vista de la constitucionalidad que le sirve de contenido legal y legítimo a las instituciones sociales, deberá responder a la movilidad social y política de los actores que socialmente se desenvuelven en el espacio público, como un espacio de encuentro con el otro.

Es necesario partir del análisis de las posibilidades materiales de reconstrucción del mundo objetivo en el que se desenvuelve la actividad ciudadana, porque sin ésta, no es posible la sociedad misma. Pero, más aún, que la interacción entre la esfera de la sociedad y la del Estado sea una interacción pragmáticamente comunicativa. Es la idea a retener, en este caso el lenguaje social y el lenguaje jurídico están interceptados por los intereses de la política. Entonces, será al lenguaje de la política a quien le tocará interpretar y dialogar sobre lo que es la justicia, el bien y la equidad para aquellos que forman parte en su condición de ciudadanos de la sociedad y del Estado. Se trata de ampliar discursivamente nuestra opinión e interpretación de lo que son las insti- 
tuciones sociales y la constitucionalidad del Estado, con el propósito inmediato, de incidir en la transformación de ambos, según sepamos dirigir nuestras conductas ciudadanas de acuerdo a principios de moralidad pública y responsabilidad ética.

A juicio de Habermas (1998a), los nuevos roles políticos que se hacen presentes en la sociedad, responden a un desarrollo de las conciencias morales más que de la fuerza del derecho positivo para hacer cumplir las normas, leyes, procedimientos y principios de autojustificación y validación de las normas. En la actualidad se requiere que el valor de la norma y sus principios de aplicación procedimental pasen por una valoración social y política que lo haga pertinente para ser aceptada por todos.

El sentido de la norma y del derecho positivo en general, es objeto de interpretación intersubjetiva, tanto en su contenido moral y público, como en su ejecución práctica, más si ella entra en contradicción con su aceptación o cumplimiento por parte de los normados. Esta postura crítica frente al Estado positivo, permite dilucidar por una parte, el nivel de estática o evolución dinámica de la historicidad del sistema social y sus determinaciones; y por otra, los mecanismos de producción y reproducción de las representaciones sim- bólicas y lingüísticas, en los que se centran nuestras creencias de que la realidad está dada o contenida por el orden normativo o el sistema de representación formal del derecho. En cuanto tal, logra la máxima concreción en el Estado; sin otras posibilidades que esas que le brinda el propio Estado donde se desarrolla, cuando, a decir verdad: lo que el derecho como instancia superestructural e ideológica del Estado- presenta como realidad, es sólo un código prescrito desde una racionalización social que atiende a intereses individualistas, pero, reagrupados socialmente, donde las propias instituciones políticas son creadas para legitimarlos.

Desde el paradigma intersubjetivo de la Teoría de la Acción Comunicativa, se abre esta posibilidad: concretar acciones comunicativas dentro de un espacio público donde el cumplimiento de los derechos políticos, genere una mayor democratización de los medios regulados para la participación ciudadana. Se trata de entender, que esta teoria social debe apuntar políticamente a una justicia con contenido material emancipatorio, y para ello, deberá estar comprometida con un ejercicio comunicativo del diálogo, suficientemente vigoroso, como para que incida de una manera contundente en la reconstrucción de otro "mundo 


\section{Zulay Díaz Montiel}

objetivo", y puedan de esta manera poliarse las libertades ciudadanas para lograr un reconocimiento pleno de la participación de todos los ciudadanos en la sociedad.

EI grado de interacción e integración social y política de los ciudadanos de una polis, se incrementará en la medida en que efectivamente puedan valerse de las normas para poner en práctica la diversidad de sus derechos, aquellos consagrados por las normas reconocidas como tales y aquellos que están en discusión para su reconocimiento. No puede entenderse el Estado como algo autónomo e indiferente de las relaciones sociales; pues, los cambios del orden jurídico con el que se regulan las interacciones sociales, dependen de las propias contingencias de las relaciones sociales que no se basan en conductas esencialistas o vitalistas, trascendentes o metafísicas; sino, en conductas que devienen de una relación en la que los actores sociales o ciudadanos, están relativizados por el contexto de la acción, que en muchos casos puede exceder la institucionalización de la misma.

Eso quiere decir que existe un rango de autonomía en el cumplimiento de las normas, y esa autonomía responde a juicios, criterios, opiniones e interpretaciones morales, sobre el sentido y el contenido de valor de las normas y sus prescripciones. Relacionar políticamente los actos de habla y las conductas sociales, en términos de moralidad pública, implica colocar la responsabilidad del ejercicio de la política en el seno de un espacio de interacci6n social, donde todos pasamos por el reconocimiento de la norma para su aceptación o rechazo. Para Habermas, la moral está implicada en el orden jurídico, es decir, en el cuerpo del derecho (1998b). Eso quiere decir, que se inscribe en el ámbito de la razón práctica. Desde ese punto de vista serán las prácticas morales las que llenarán de contenido, de valor a las normas jurídicas, en tal orden de ideas, se pudiera entender que en esa medida sólo en un orden de libertades públicas, es donde la sociedad se puede desarrollar y se puede perfilar un código jurídico, o un sistema de derecho, que responda a las expectativas de una vida ciudadana convivida por la mayoría de las personas.

Es decir, un ejercicio comunicativo para actuar en libertad desde el diálogo en la diversidad, es una condición básica para una teoría social que promueva una sociedad más justa y emancipada, puesto que permite cada vez más, mayores niveles de participación social que hacen 
mucho más viable una democratización de la democracia. De este modo es posible crear espacios de interacción, donde se puedan coordinar acciones mancomunadas que hagan realidad el desarrollo de nuevas sociedades fundadas en la institucionalidad del diálogo y la razón prácti$\mathrm{ca}$, como principios reflexivos motivantes y reguladores, de los sistemas de conductas de los que depende el desarrollo de lo social y estatal.

Coordinando medios-fines a través de acciones comunicativas, las acciones sociopolíticas a devenir construirían una realidad social que se hace desde un mundo objetivo, fundado por la intersubjetividad, devolviendo así el sentido social a las acciones orientadas al éxito, desde acciones orientadas por el entendimiento y no al revés. Además, contextualizar la crítica que se hace desde la pragmática comunicativa a las realidades sociales previamente codificadas, es afirmar y demostrar, que la integración social sólo es posible a partir de las interacciones sociales entramadas desde un mundo de vida que las siente; $y$ las instituciones políticas, deben ser un reflejo de éstas.

Las relaciones políticas entre sociedad y Estado, deben ser entendidas en términos de razón práctica, es decir, en juicios de valor y de acti- tudes disuasivas y consensuales; de ninguna manera en relaciones de coacción y de fuerza. Se requiere distinguir el aspecto procedimental de regulación legal en el que se basa el derecho y en ello va el carácter constituyente al Estado de derecho, de aquella legitimación que se le otorga desde la práctica social del derecho que parte del referente de moralidad pública que considera al derecho y al Estado, como el desarrollo de instituciones basadas en la soberanía popular, la autonomía de los individuos y la capacidad de éstos de crear una voluntad común mediante el ejercicio de la libre opinión y discusión en el ámbito público (Boladeras, 1996: 135).

\section{Kazan práctica de la dimen- sión comunicativa y morali- dad en el diálogo público}

En respuesta a las crisis de la sociedad moderna, los mundos de vida de los individuos se van a caracterizar por la emergencia de una autonomía de la voluntad para actuar libremente, ya que hasta ahora, han sido sometidos a la esfera del control y los intereses de la racionalidad medio-fin. La consecuencia del avanzado desarrollo tecno-cientista que se ha logrado en las sociedades neoliberales se percibe en la reduc- 


\section{Zulay Díaz Montiel}

ción que sufre el campo de la razón práctica en la formación de la conciencia moral, las conductas éticas y las prácticas discursivas. Este intento por aniquilar lo constitutivo del ser humano, es decir, el contexto y las relaciones morales de dónde los individuos derivan juicios de valor $y$ razones morales que les permitan lograr acuerdos y convenios, argumentos y opiniones sobre lo que debe ser y significar el entendimiento racional de las acciones vividas y compartidas niega expresamente las condiciones fácticas para que las acciones comunicativas con pretensiones de entendimiento se puedan realizar de modo imparcial, legítimo y justo.

El desafío que se le presenta a la razón práctica, entendida sólo en su sentido pragmático, que tiende a la adecuación medios fines, según las relaciones empíricas y las técnicas de elección racional; es superar y cancelar ese orden de dominio donde sólo predomina la función instrumental de la razón tecno-cientista, puesto que la voluntad de acción puede ser regulada o administrada por la voluntad común de ciudadanos, que nutra el interés de control parcial por parte de grupos, partidos, clase o institución.
Frente a esta hegemonía de la racionalidad técnica presente en las sociedades capitalistas, se puede considerar que desde el punto de vista del pensamiento de Habermas, serán los contenidos morales de la razón práctica, los que determinen el uso emancipador de la racionalidad cuando esta cumple fines éticos y libertarios. Pero esos fines, se lograrán a través de proyectos pragmáticos que le den un sentido dialógico y alternativo a los diversos procesos comunicativos que se desarrollan en la sociedad. Es a través de ese diálogo con el otro y de la pluralidad de opiniones de los juicios, que se hará posible una relación comunicativa entre los individuos de una sociedad, siempre que atiendan a los requerimientos, exigencias y obligaciones, asumidas desde un punto de origen y encuentro entre ellos.

Esto permitirá una libertad de acción y actuación, convenida social, política y lingüísticamente, de acuerdo a la diversidad de intereses particulares en razón y beneficio de otros más generales, universales y consensuados. Precisamente, el logro de acuerdos racionales moralmente validos para la mayoría supone, por una parte, no solamente condiciones fácticas que implique o garanticen los niveles de posibles acuerdos a 
partir de las diferencias; sino, por la otra, el reconocimiento de una voluntad de comprensión que debe actuar entre todos los que participan para llegar a fines comunes o compartidos. Por tanto los contenidos prácticos de las acciones que se producen en la interacción social quedan revestidos por la presencia de la ética personal, social, comunicativa y discursiva, que es lo que podrá generar ese sentido de la acción: hacia un deber ser donde se interceptan y comparten los diversos mundos de vida de cada individuo o particularidad, hacia relaciones más plurales de coparticipación e integración ciudadana y política.

Desde ese punto de vista, es muy acertado lo que señala Boladeras, al decir que el discurso moral exige un paso más: el distanciamiento de la subjetividad del mundo de vida y la asunción de una intersubjetividad abstracta, que permita alcanzar la universalidad necesaria del discurso moral. La universalidad moral supone el punto de vista "imparcial" de una voluntad que asume las distintas perspectivas subjetivas, sin eliminarlas, delimitando la perspectiva de todos y cada uno con la de los demás.

EI uso moral de la razón práctica nos pide que ampliemos el campo interno de referencia de nuestra voluntad al ámbito general de la comunidad de comunicación que constituimos todos los seres humanos. Y la característica fundamental de esta ampliación consiste en que se asume "sin coacción", como realización libre de una voluntad autónoma, que decide trascender sus intereses particulares y asociarse a la voluntad general. De ésta depende el equilibrio y el desarrollo de las relaciones intersubjetivas (Boladeras, 106).

La sociedad actual, es un escenario de relaciones altamente conflictivas, porque estas relaciones se basan en un sistema de dominio cuyo poder se afianza y recrea por medio de una racionalidad que piensa teológicamente el destino y la historia de las sociedades humanas, en términos de represión, sublimación, coacción, donde los beneficios económicos de la conversión de la tecno-ciencia en política, determinan principalmente su desarrollo. Las necesidades y las condiciones de vida de los seres humanos pasan, en el mejor de los casos, a un segundo plano. Es necesario señalar, que la concepción antropológica que se tiene de las relaciones humanas en estas sociedades del capitalismo maduro o posindustrial; es una concepción de la exclusión y explotación del hombre, considerado como mercancía y objeto de la producción. Se podría decir que la críti- 


\section{Zulay Díaz Montiel}

ca formulada por la teoría marxista no ha perdido en su "esencia" el carácter delator de un sistema de producción y de beneficios sociales, que son el resultado de una sociedad antagónica y contradictoria, donde cada vez más la utilización de criterios cientificistas son requeridos y expuestos para acreditar las conquistas de la racionalidad funcional o estratégica.

Es un perverso intento de organizar el sistema social según principios técnicos que puedan prever y predeterminar las acciones sociales como si fueran simples funciones de un sistema que se ejecuta jerárquica y programáticamente. En estas sociedades, se vuelve un imperativo de la comunidad política constituida por el Estado y la Sociedad Civil, la organización de la Sociedad Civil en el espacio público para denunciar la ficción de la razón científica como razón soberana, y del mismo modo, la alienada existencia de seres humanos sumidos bajo el yugo de relaciones infrahumanas.

Es indispensable cuestionar la legitimaci6n de los regímenes de poder institucionalizados por parte del Estado, como respuesta a un problema político que debe ser resuelto desde una participación social generalizada donde sea tarea de todos el rescate de la moral pública como un medio de acceso a prácticas ciudadanas enmarcadas en el reconocimiento de los derechos humanos. Es de este modo, y no de otro, que se puede construir a partir de un ideal de justicia, aquellas acciones referidas a hechos de justicia, es decir, a actos justos que valgan para unos y otros, ya que entre unos y otros, queda establecido el acuerdo y la validez para todos. De este modo, la noción de poder y de fuerza política, ya no reside únicamente en la gestión del Estado y en su proyección hacia el orden social; sino, por el contrario, resulta de ese universo de acciones intersubjetivas, donde los individuos quedan comprometidos en relación a lo que es el bien común para todos y no para un sector de la sociedad.

El ideal de una justicia equitativa puede ser cumplido fácticamente a partir de un sistema de relaciones entre ciudadanos que es de orden axiológico y discursivo. Se apunta a un "deber ser" que es sinónimo de hechos justos; entonces, se debe dar cumplimiento a estas acciones entre todos, puesto que el interés de todos, esta debatido y asumido comprensiblemente como un fin común que permite lograr un mayor nivel de igualdad y equidad en las relaciones sociales.

La aproximación deontológica a lo que puede ser justo, implica una 
mínima base material y existencial que sirve de plataforma para la realización de la justicia como posibilidad de hacer real y concreto el bien social para cada uno de los individuos. Porque la justicia, además de portar un valor ideal, es también una condición de vida necesaria para los seres humanos. El logro de ella pasa, de igual modo, por un sistema de significación discursiva y prácticas sociales, que colocan en la vida pública el debate ideológico y político que abre la discusión e interpretaciones de las concepciones que se tienen de la justicia.

Hablar y discutir sobre el significado de lo que es la justicia, discernir sobre las condiciones acerca de lo que son las acciones y los actos justos, requiere de un lenguaje y una hermeneútica acerca de los contenidos de valoración moral, social y política, con los cuales interpretamos, esto o aquello, a lo que nos referimos en términos de justicia. La estructura discursiva de la que nos valemos para comprender la justicia como una acción que forma parte de la razón práctica, compromete nuestro discurso con la representación que se elabora de la justicia a nivel de las instituciones sociales. La justicia como ideal y la justicia como discurso, entran a formar parte del espacio público y de la moralidad, y se debe considerar como un asunto evidentemente político del que todos formamos parte y tenemos responsabilidades. Así, la justicia se convierte en código y norma de conducta, en sistema y organización jurídica, en procesos de reflexión y crítica acerca de la aplicación de las leyes, los derechos humanos, decisiones y elecciones políticas que deben ser discutidos dialógicamente y legitimados al interior del cuerpo social que es cada uno de los ciudadanos (Habermas, 1996).

Para construir una verdadera interacción social que nos relacione en un sentido pragmático y práctico, debemos darnos a la tarea de crear políticamente una comunidad lingüística que nos permita desarrollar aquellas competencias discursivas necesarias para la interpretación y solución de los problemas. Además, profundizar el potencial racional para lograr acuerdos a partir de nuestra inserción en la discusión pública de los asuntos del Estado, nos abre la vía para una comunicación crítica y plural. La nueva ciudadanía y los ejercicios de derechos democráticos, no pueden ser planteados y reconocidos en cuanto tal, si no se hace efectivo un proyecto de intervención social que tienda a revalidar la acción dialógica de la razón práctica sobre la 


\section{Zulay Díaz Montiel}

acción estratégica de la razón tecnocientista.

Para ello, es irreductible la interacción lingüística como praxis humana, porque sólo por medio de ella es que podemos acercarnos a un modelo de formación no coactivo de la voluntad común y convertirnos en una comunidad de comunicación sujeta a la necesidad de cooperar (Habermas, 1999: 352). A través del diálogo reflexivo podremos reconstruir la institucionalidad política como representación simbólica de interacciones sociales manejadas con niveles de justicia práctica, que enfrenten la sumisión de la esfera política a una racionalidad técnica.

En la medida que somos más reflexivos, repetimos con Habermas, desarrollamos un potencial racional de entendimiento lingüístico capaz de favorecer e incrementar los procesos racionales de entendimiento. En eso radica el poder del diálogo que parte de la acción comunicativa con el otro; porque, precisamente, a mayor esfuerzo reflexivo, mayor será la necesidad que tendremos de entendernos racionalmente con el otro. La condición de racionalidad que subyace en el discurso entre quienes se comunican, es un supuesto universalista del que dependen los actos de habla. La interlocución no puede hacerse efectiva, si previamente no se postula el interés e intención de actuar comunicativamente; es decir, de manejar un lenguaje cuyos contenidos cognitivos puedan ser interpretables en el marco de un mundo de vida que puede ser compartido sin dejar de respetar las diferencias.

En este punto, los interlocutores se encuentran "cara a cara" con una acción práctica signada por el entendimiento, lo que hace suponer que los procesos discursivos y los contenidos morales de la acción comunicativa, sobre los que se desarrolla el diálogo que permite discutir sobre los diversos asuntos públicos de la sociedad, requieren de una participación abierta e intersubjetiva.

Pero la necesidad de entendernos no se satisface atendiendo a un acto personal del entendimiento. La comunicación busca un desideratum público porque este tipo de acción comunicativa está situada en un espacio con el otro que es el espacio público de interacciones sociales y representaciones institucionales, que exigen, de alguna manera, una concordancia o coherencia entre los dos sistemas de acción y comunicación: del Estado a la ciudadanía y de esta al Estado. Es decir, al hacerse "pública" la acción dialógica de la comunicación, transforma la política en un espacio para la argumentación de los 
intereses y fines, para dar y recibir conocimiento de las razones que nos sirven para la afirmación o negación de los argumentos en disputa.

Se aumenta de este modo, la posibilidad de disentir y consentir, y se evita el riesgo de que el dinero y el poder, sean utilizados como medios sistémicos para sustituir el lenguaje como medio de entendimiento, sobre todo, como mecanismo de coordinación de la acción con intención comunicativa en contextos delimitados, donde la pertinencia y la validez del habla, admite un reconocimiento compartido y evita las falacias de la retórica y la demagogia" de la política (Habermas, 1999) ${ }^{1}$.

La práctica moral del derecho exige una transformación del Estado liberal en términos de prácticas sociales emancipatorias... Es decir, prácticas asociadas a valores de libertad. Así es que la política como espacio de formaci6n y desarrollo de la conciencia democrática de quienes desarrollan conductas cívicas y éticas, se puede legitimar institucionalmente. Porque, precisamente, además de la fuerza fundante que legalmente es propia del derecho para crear las normas y sus valores, los valores prácticos de las normas que están contenidos por las acciones sociales de quienes las cumplen, deben estar reconocidos y aceptados públicamente en la sociedad. La democracia política vendría a ser la genuina condición de vida del derecho, en términos de prácticas morales. Eso implicaría una interpretación del derecho y de las instituciones públicas del Estado, desde una perspectiva mucho más participativa y directa de la ciudadanía como Sociedad Civil. La validez jurídica del derecho como algo autónomo e independiente,: no puede estar fuera de la esfera de la política y de la moral pública (Habermas, 1981).

Ese tipo de racionalidad instrumental positiva en la que descansa la sociedad liberal y sus instituciones, no ha podido garantizar relaciones entre Estado y sociedad que sean lo más justas posibles. Se presume que la justicia en sí misma (sustantiva), es condición para el ejercicio de las libertades y el reconocimiento de la igualdad. Pero la realidad histórica es otra, porque no se le reconoce a los ciudadanos prácticas políticas que

1 "Medios como el dinero y el poder pueden ahorrar en buena parte los costos que entraña el disentimiento, porque desligan la coordinación de la acción de la formación lingüística de un consenso, neutralizandolo frente a la alternativa acuerdo/falta de entendimiento. El acuerdo alcanzado comunicativamente y el disentimiento dependen del reconocimiento intersubjetivo de pretensiones de validez susceptibles de crítica". Cfr. Habermas, J. Teoría de la acci6n comunicativa, España, Taurus. 1999: 352. 


\section{Zulay Díaz Montiel}

pongan en evidencia las fallas o debilidades, los errores y contradicciones, que pueda portar el sistema jurídico $y$ que inevitablemente debe ser enfrentado desde acciones y conductas que son contrarias a las leyes y las normas instituidas.

Acoger principios de libertades políticas, en términos de prácticas ciudadanas, implica democratizar al Estado, desde juicios morales que reforman y transforman casi por completo, los contenidos de valor que en un momento sirven para actuar e interpretar la justicia. Ya desde Aristóteles la filosofía práctica es la filosofía material que tiene que ver con las virtudes y valores de la vida. Es la vida que se convive junto a los otros, es la vida justa que se hace desde la acción práctica de los hechos que se corresponden a los valores de la justicia. Esa es la acción concreta que se construye a partir del ideal: las relaciones políticas que adelanta en una sociedad su ciudadanía, es la que le porta al derecho su contenido y del que siempre debiera servirse. Son relaciones intersubjetivas que terminan sobreponiendo al concepto objetivo del derecho, la significación subjetiva con la que se hace interpretable el valor de las acciones. Entre derecho y moral, considera Habermas, debe existir una relación procedimental sin excluirse una de la otra.
Sin embargo, es por cuestiones morales, razones, juicios y críticas morales, que el derecho es objeto de consideración por parte de una sociedad que se organiza cívicamente para adelantar su continua reorganización y legislación (Habermas, 1981).

Se trata de ver a todas luces que las acciones morales amplían y extienden el campo de la responsabilidad, la imparcialidad, la ética y la justicia, hacia mayores sectores sociales y hacia más derechos políticos, sociales y económicos, para todos aquellos que buscan igualdad de condiciones en la sociedad donde conviven. En las instituciones no pueden quedar solamente contenidas las fuerzas de coacción, restricción y obligación del Estado, revelado a través del derecho. Es importante destacar que ese orden legal debe estar legitimado por la correspondencia que debe darse con el ciudadano, entendido este, como un actor en la formación de la opinión pública y la formación de la voluntad colectiva. Alguien que es capaz de incidir e influir en la interpretación y la acción dialógica que requieren las instituciones para que cumplan los fines para los que han sido creadas.

No es suficiente la condición coactiva que cumple el derecho en las praxis públicas, adoptar otras alternativas para entender la coac- 
ción supone una relectura de los contenidos coactivos del derecho positivo o moderno en los que los valores intersubjetivos de la aceptación del rango coactivo de la norma, sea deliberativo y negociado de acuerdo a fines comunes. Eso permite entender, desde otros ámbitos de la política, la libertad para actuar que se construye el ciudadano de acuerdo a sus necesidades, resistencias y aceptaciones, que considera le merece el cumplimiento legal y moral de las normas. El sentido universalista que contiene la norma en su valor de justicia debe recoger la acción individual y colectiva de quienes buscan y desean actos y hechos justos. Así, recogemos esta cita de Habermas a través de Julio De Zan-, "cada norma válida habrá de satisfacer la condición de que las consecuencias y efectos secundarios que se seguirán (previsiblemente) de su acatamiento universal para la satisfacción de los intereses de cada uno puedan ser aceptados por todos los afectados" (2002: 90).

La adopción en común de perspectivas sobre el ejercicio de la ley de la justicia debe concebirse desde un enfoque intersubjetivo que reconstruya las instituciones políticas, desde un discurso pragmático no coactivo de la voluntad común, para llegar a formar una comunidad de comunicación sujeta a la necesidad de cooperar. Para ello, el poder político institucional debe velar por la legitimidad de las leyes. La justicia como dimensión de la validez puede dar prioridad a lo justo ante lo bueno, a manera de proteger la libertad, solidaridad e integridad ciudadana. Además, el cuidar responsablemente de un discurso práctico con sentido individualista de la igualdad, es tarea de toda sociedad que rescata lo fundamental de buscar la integración social. Los intereses y derechos en conflicto, deben ser tratados desde la perspectiva de todos, sin exclusión.

Hay que aprender a distinguir entre intereses generalizables y particulares; y la justicia como praxis emancipadora puede ayudar a enfrentar los problemas de autocomprensión de los sujetos. Para ello, los juicios morales deben coadyuvar a los procesos de socialización que forman a los miembros del sistema social como sujetos capaces de lenguaje y acción, desde el requerimiento de justificación de las normas. No obstante, partir de la intersubjetividad de la praxis, sólo será posible a través de la autorreflexión que emancipa al sujeto. No se puede sentir lo que otro siente, sin antes haber comprendido por medio de la reflexión, que el otro, 


\section{Zulay Díaz Montiel}

es otro desde la perspectiva del YO fundante, que todo lo crea, lo excluye y lo incluye, haciendo posible su socialización a través del otro.

AI respecto, Habermas plantea que sólo como participantes en un diálogo inclusivo y orientado hacia el consenso, se requiere de nosotros que ejerzamos la virtud cognitiva de la empatía hacia las diferencias con los otros, en la percepción de una situación común (Habermas, 2003: $23)^{2}$. Es decir, el paso de una reflexión monológica al diálogo, deberá fundar una nueva racionalidad que no dependa ya directamente del sujeto, sino, más bien, de las relaciones interpersonales que ese sujeto establece para formar un "nosotros". En este sentido, el mundo moral que nosotros como personas morales debemos hacer realidad conjuntamente, sólo es factible, desde un significado constructivo (Habermas, 2003: 87) ${ }^{3}$.

Las condiciones de comprensión intersubjetiva deben fundarse en un concepto de autonomía que trascienda lo subjetivo y se inserte en lo intersubjetivo y, desde allí afirmarnos como seres libres e iguales. Sin embargo, las convicciones morales de acuerdo con Habermas sólo moverán la voluntad si están insertas en una autocomprensión ética que enganche la preocupación por el propio bien al interés por la justicia (Habermas, 2002: 14) ${ }^{4}$.

2 "La voluntad de una persona se ve afectada por razones que deben contar igualmente para todas las demás personas (en la medida en que sean vistas como miembros de una comunidad moral). Esta interpenetración de la voluntad libre y la razón práctica permite concebir la comunidad moral como una comunidad inclusiva y autolegisladora de individuos libres e iguales, que se sienten obligados a tratarse unos a otros como fines en sí mismos." (... ) "Lo que obliga a los participantes en el debate práctico es la fuerza vinculante de un tipo de razones que se supone deben convencer igualmente a todos los demás (no sólo razones que reflejan preferencias mías o de otras personas, sino razones a la luz de las cuales todos los participantes podrían descubrir conjuntamente, frente a cualquier cuestión que necesitara regulación, que tipo de práctica responde igualmente a los intereses de todos".Véase:HABERMAS, J. La ética del discurso y la cuesti6n de la verdad, Coloquio con Jürgen Habermas. (Paris IV, Sorbona, 1 de febrero de 2001), España, Paidós, 2000: 23-29.

3 Ibíd.: 87."Esto explica por que la proyección de un mundo social inclusivo caracterizado por unas relaciones interpersonales bien ordenadas entre miembros libres e iguales de una sociedad que se autodetermina sirve como sustituto para la referencia ontológica a un mundo objetivo".

4 "Puede que haya teorías deontológicas sucesoras de Kant que expliquen cómo fundamentar y aplicar las normas morales, pero aún nos adeudan la respuesta a la pregunta de por qué debemos en definitiva ser morales". Cfr. HABERMAS, J. El Futuro de la Naturaleza Humana, Hacia una eugenesia liberal, España, Paidós, 2002: 14. El autor entiende por razones morales:"aquellas que pueden contar racionalmente con ser aceptadas en una sociedad cosmovisivamente pluralista" (Ibíd). 
Bajo este punto de vista, las razones morales son las únicas que nos pueden emancipar de la cosificación en la que estamos sumergidos. Es cuestión de poder comprender que en este momento de crisis por el que pasa la institucionalidad de las sociedades modernas, las consideraciones normativas que afectan a la formación democrática de la voluntad, dependen de la autocomprensión que tengamos nosotros mismos de los nuevos espacios de decisión que participativamente deberíamos construir desde una praxis dialógica y multicultural, donde consideremos la sociedad como el escenario natural de la convivencia, regulado por prácticas políticas que nos permitan interactuar en condiciones de libertad, equidad e igualdad, pues, la responsabilidad y respeto mutuo nos lo debemos los unos a los otros.

La praxis objetivadora que ha quebrado la tradición, la cultura e historia de nuestros mundos de vida, nos ha hecho inconscientes de las regulaciones morales que deben regir nuestras conductas y de la crítica que se debe formular al racionalismo técnico, que se presenta como única posibilidad de ser racionales. Las reflexiones normativas que en el espacio público se discutan, deben coadyuvar al desarrollo de una noción de ciudadanía multicultural que desde la pluralidad de la razón dialógica defina los derechos civiles, tomando en cuenta los contextos culturales de cada uno de nuestros pueblos, haciendo referencia a la justicia desde el punto de vista moral con el que se califica el interés individual con respecto al interés de todos, y para ello debemos reconocernos por encima de las propias barreras subculturales, a través de una cultura política a la que todos tengamos acceso y derechos de participación.

La razón práctica de la dimensión comunicativa al no desplegarse a través del lenguaje, como medio intersubjetivo, dará significados a la concepción de un mundo inspirado desde la formación democrática de la voluntad política para crear una moral autónoma, que atienda a nuestra comprensión antropológica. Los juicios morales a los que haya lugar, tendrán que comportar acciones morales que nos hagan crear esa visión de mundo que se arraiga en una cultura política en donde las decisiones tomen en cuenta los valores creados y compartidos para sostenerlas.

Hay que desarrollar un lenguaje multicultural que haga posible que esa cultura política resulte de nuestro propio discurso teorico-práctico. 


\section{Zulay Díaz Montiel}

Para ello, las cosas que es justo hacer deben estar facultadas por una razón práctica intersubjetiva, que desate la autonomía desde la tradición para hacernos sensibles a nuestra propia inmanencia moral. Es decir, los fundamentos normativos de la integración social, deberán constituirse desde las transparentes estructuras comunicativas de nuestros mundos de vida. Debemos aspirar a mejores condiciones de vida, debemos salirle al paso al analfabetismo, al desempleo, a la pobreza material y también a la pobreza espiritual que coarta nuestra voluntad política y la fragmenta.

Hay que aspirar a una formación democrática radical de la voluntad, que no intente separar la política de la moral. Más que tener buenas razones para ello, de lo que se trata es de tener una relación existencial fundamental de querer ser nosotros mismos (Nino, 1997: 154) ${ }^{5}$. Hay que ubicar el valor de la democracia en la moralización de las preferencias de las personas como única forma de alcanzar una filosofía práctica del poder y su autentica representación institucionaI, que nos permita descubrir e incrementar las nuevas condiciones sociales, los requerimientos económicos, las practicas políticas, el concepto de justicia y libertad moral, con los que construir nuevas relaciones humanas de interacción y solidaridad, asociada a la paz y al bien común, se inserte en la validez de las instituciones y los principios que las sostienen.

\section{Racionalidad política de las instituciones e integración socio-cultural}

En la modernidad, la política se redujo a mero poder de coacción más que a adhesión y/o acción común. La separación entre lo político y lo social desvirtuó el carácter de la política como un saber orgánico acerca de fines prácticos (Prados, 1989: 89) ${ }^{6}$; es decir, como racionali-

5 "Desde mi punto de vista, el valor de la democracia reside en su naturaleza epistémica con respecto a la moralidad social. Sostengo que, una vez hechos ciertos reparos, se podría decir que la democracia es el procedimiento más confiable para poder acceder al conocimiento de los principios morales. Por ello, esta posición no constituye una visión perfeccionista, pues presupone una diferenciación entre los estandares morales, limitando el valor epistémico de la democracia a aquellos que son de naturaleza intersubjetiva", Cfr. NINO, C. La constitución de la democracia deliberativa, España, Gedisa, 1997: 154

6 El autor refiriéndose al saber político plantea que:"en definitiva, se procede como si no se estuviera considerando una realidad de la que nosotros mismos somos su principio, una realidad práctica."Véase: PRADOS, A. Ethos y Polis. Bases para una reconstrucción de la filosofía política, España, Ediciones Universidad de Navarra. Colección filosófica, No. 152, Facultad de Filosofía y Letras, Pamplona, España, 1999: 89. 
dad del propio sujeto como agente. Esta separación abrió el tratamiento de lo político desde dos perspectivas: la sociológica y la jurídiconormativista.

En este sentido, Prados refiere que desde la perspectiva sociológica, lo político es considerado como un fenómeno social más el fenómeno del poder; mientras que, desde una perspectiva juridiconormativista, el saber político es entendido como un conocimiento acerca de la construcción de una estructura legal, de un organigrama normativo, que somete a una medida racional ese fenómeno social que es el poder. Así, a lo sociológico se le impone una racionalidad jurídico-formal, independientemente de su condición ético-política (Prados, 1999: 90) ${ }^{7}$.

Lo anteriormente expuesto, conlleva a suponer que en la moderni- dad lo político, como naturaleza práctica del ser humano, lejos de constituir el sentido de la acción social integradora, se convierte en artífice de una racionalización social, objetivada desde la propia realidad de la acción. La racionalidad práctica de la política, queda escindida así de la vida política y de todo razonamiento moral en la política para generar un colectivo desde la acción común.

Asimismo, se puede considerar a juicio de Prados (Op.cit: 91) ${ }^{8}$, que la realidad social y política que los clásicos entendieron como forma de vida y que expresaron con el concepto de politeia, en la modernidad se ha ido desvaneciendo en el tiempo, porque el Estado ha hecho una autoabsorción de una esfera sobre otra hasta neutralizarlas, lo que le resta evidentemente competencia a cada

7 Ibíd.: 90-94. Afirma que un enfoque no invalida al otro,"sino que lo supone; y únicamente postula un cambio en el tipo de racionalidad que ha de prevalecer. Sobre la racionalidad sociológica ha de imponerse la racionalidad legal-formal; sobre lo fáctico y dinámico ha de actuar, como sujeción, lo estructural y normativo. Se trata, por tanto, de someter lo político -que sigue siendo concebido como facticidad, como puro hecho volitivo- a una racionalización extrínseca, que es obra de la racionalidad jurídica. Lo político es domesticado por una razón separada de ello, que actúa desde fuera, es decir, por una razón que obra como razón técnica." En este sentido el autor plantea que: "El saber político queda así entendido como saber sobre la polis: sobre una realidad que recibe pasivamente el influjo de ese saber. Pero no es entendido como saber de la polis: el saber que ésta como comunidad activa posee y con el que orienta su propia actividad; en otros términos: un saber que consiste en saber obrar."

8 Ibíd.: 91. “El saber político, la racionalidad política, nada tiene que ver con la mejora del hombre, con la formación del carácter. Su cometido es la construcción de una estructura de reglas articuladas por una 1ógica propia. Pero un orden político que no necesita de la moralidad de sus ciudadanos, tampoco promueve esa moralidad. Política y ética quedan separadas: la primera se desvincula de los fines personales; la segunda se independiza de las exigencias colectivas." 
una de las esferas para desarrollarse e interactuar. Esa confiscación de las dinámicas sociales por la institucionalidad del poder político como política de reconocimiento e identidad social en el que se ampara el Estado para generar sus acciones de gobierno, es decir, como sociedad política expresa, va en detrimento de lo que podríamos definir como construcción de la ciudadanía pública.

Acá se trata de poner a la luz del análisis, ese perverso fenómeno de fuerza con el que el Estado toma posesión de la sociedad y se hace presente de una manera que disminuye el rol de autonomía y participación de la ciudadanía, sobre todo cuando esta le es adversa o beligerante. Un auténtico Estado de derecho debe ejecutar políticas de integración socioculturales, que favorezcan el desarrollo de la opinión pública de la ciudadanía en contraste y crítica con las direcciones del Estado.

Liberar de la coraza institucional la racionalidad política del Estado positivo, ya que este Estado en sí mismo, no es capaz de autogenerar las condiciones de su propia transformación pública, demuestra con gran pertinencia que las tesis de Habermas acerca de la dimensión instrumental de tal racionalidad, solamente pueden ser superadas por un proceso de deliberación discursiva y una democratización política de los intereses emancipatorios, que den paso a voluntades morales y públicas cuyos fines sean los de generar a nivel institucional nuevas coordenadas de acción sobre las situaciones sociopolíticas, que deben ser interpretadas y resueltas por los ciudadanos.

No es posible ninguna superación de las limitaciones del Estado social moderno, sin ampliar la práctica política que le sirve de legitimidad hacia una dimensión de la racionalidad práctica por medio de la que la ciudadanía asume su rol protagónico como sujeto del desarrollo social, desde su actuación etico-política. Es en este terreno de la participación pública y en el marco de la institucionalidad política, donde el Estado moderno mantiene su residencia para que la ciudadanía entre a formar parte del ejercicio de los derechos y libertades políticas que aún no se le reconocen.

No existe otro lugar para la acción y en consecuencia para el despliegue de una racionalidad política que esté caracterizada por la legitimidad racional en la que deben basarse cualquier elección y decisión, arbitraje y convenio, entre los ciudadanos y entre éstos y el Estado. En otras palabras: se apela a la razón y a la 
autonomía de los individuos como fuente de legitimación, a la discusión pública de los conflictos de intereses y a la definición de objetivos comunes, para que concreten la voluntad de la soberanía popular, como resortes insoslayables de los mecanismos sociopolíticos democráticos (Boladeras, 1996: 136).

Es importante advertir que una racionalidad impuesta desde una acción ordenadora, como lo es la acción jurídica del Estado, no puede pretender dar cuenta de la racionalidad de la acción política como racionalidad práctica, ya que es al propio sujeto de la acción al que se le invalida sobreponiendo ante el, una razón que nada tiene que ver con sus razones, como sujeto de acción política. Es decir, las razones de lo político no median en la validez de las exigencias y propósitos de los ciudadanos en un contexto específico (Boladeras, Ibíd: 97) ${ }^{9}$.

Ahora bien, si ante lo descrito afirmamos que la vida política de un pueblo es su vida institucional, como forma concreta y práctica desde donde se puede transformar su esfe- ra sociocultural y viceversa, nos situamos en un contexto de posibilidades donde los ciudadanos como sujetos de la acción política se hacen capaces de articular desde la propia institucionalidad instituida, la transformación de ésta. Así, la acción política, como acción que instituye la sociedad, es acción institucionalizadora que define su propia naturaleza política.

En la medida en que se democratice el orden institucional desde la propia racionalidad política de los ciudadanos que la instituyen, en esa misma medida se hace de suyo la transformación institucional necesaria como principio activo de las acciones políticas de sus ciudadanos. De esta manera, la sociedad crea su propio contenido de vida en la polis y nos hacemos capaces de crear una sociedad política como realidad humana. Sólo la autonomía de las acciones políticas nos harán libres, realizando los valores que nos hacen ser humanos.

En Latinoamérica, por ejemplo, a comienzos de la década de los ochenta comienza a surgir un nuevo orden

Ibíd.: 97. La modernidad lleva a entender la racionalización de lo político como sometimiento de lo político a la racionalidad de lo no político. Racionalizar lo político significa, por tanto, despolitizarlo. Y esta despolitización tiene dos aspectos: la eliminación del carácter práctico de lo político, trivialización de la acción política; y la eliminación de su índole arquitectónica." Cfr. Boladeras, M. Comunicación, ética y política. Habermas y sus críticos. Tecnos, Madrid, 1996: 97. 


\section{Zulay Díaz Montiel}

político que pasa del repudio de gobiernos militares y dictaduras, a instituir democracias constitucionales. Con ello, ha surgido también un proceso de transformación de la cultura política en sociedades despolitizadas e inmersas en pobreza extrema, desigualdades e injusticias, que buscan soluciones y con ello, han hecho surgir una ciudadanía que comienza lentamente a constituir una nueva Sociedad Civil. Por supuesto, sin pretender bosquejar las diferencias entre los diversos contextos sociopoliticos, podemos observar en líneas generales, que en Latinoamérica, aunque todavía con un mínimo de participación procedimental, surge una racionalidad política desde la propia reflexión del ciudadano.

En este acontecer, la Sociedad Civil nace para mediar entre lo público y lo privado, deliberando abiertamente asuntos en defensa de intereses generalizables. Cohen y Arato, explican que una Sociedad Civil autorreflexiva de su propia accion política, modifica el modelo de sociedad política, porque su tarea se convierte en puente móvil para contrarrestar la anomia societal (2002: 75). Y en este sentido, aunque existen serias deficiencias, no por ello, se puede dejar de afirmar que en Latinoamérica comienza a instituirse la figura del ciudadano, y este por su propia naturaleza dialógica e intersubjetiva, comienza a sentir la necesidad de una práctica política democrática, más alla de lo que hasta ahora eso ha significado en la praxis política de nuestros pueblos.

Deliberar acerca de lo que nos podría conducir a la construcción de principios de moralidad social, como presupuestos democráticos, exige que se cumpla una justicia social como mecanismo de acción política concreta, desde la racionalidad política de las instituciones del Estado. Sin esta presencia del Estado en su condición fundante del orden constituyente de las normas y leyes que deben orientar las acciones ciudadanas hacia el bien compartido y la justicia práctica; no es posible que se genere una voluntad política, pública y ciudadana, con intereses emancipatorios que le valgan a éstos para actuar en el seno de unas relaciones sociales donde el poder gire en torno a una voluntad común libre de dominación, pero, a su vez, asociada a procesos comunicativos y discursivos que le sirven para definir los horizontes de las acciones sociales compartidas.

Para ello, la autocomprensión hermeneútica de nuestro proceso sociocultural será indispensable, aunque no suficiente, para afianzar la 
autonomía que como pueblos soberanos debemos usar para generar un proceso de formación ciudadana enmarcado en un contexto de tradiciones que nos hace latinoamericanos. La argumentación moral desde donde sostengamos políticamente nuestra autonomía, hay que desarrollarla desde un esfuerzo cooperativo y respeto mutuo, que nos invite al diálogo intersubjetivo.

Habermas (1993: 68), explica que las interacciones comunicativas por medio de las cuales se coordina en el espacio público la argumentación cuya finalidad es el consenso, requiere como terminus ad quem el acuerdo (vestiindigung). El discurso práctico moral debe institucionalizar aspectos de lo que es justo y solidario para efecto de transformar la racionalidad práctica que dirija las acciones a seguir. Obrar políticamente desde la autonomía de los juicios morales, es lo que puede coadyuvar a la integración social, atravesando el acuerdo de todos a quienes afecta. Adoptando el punto de vista moral, se pueden obtener soluciones a través del diálogo, referidas a intereses generalizables que las cuestiones de justicia poseen en su estructura, permitiendo atender de manera ponderada e igualitaria el interés de todos. La cooperación y el respeto mutuo, postulan un estadio superior de responsa- bilidad que se hace reciproca, por lo que la autonomía total de la razón práctica se hace intersubjetiva.

El permanente desafío de constituir una ciudadanía deliberante implica obtener una autonomía moral concretada en los juicios morales que nos lleven a establecer reglas de cooperación constitutivas de lo intersubjetivo, como forma de establecer normas que han de concebirse en el espacio público desde el diálogo. A través de la cooperación y el respeto entre iguales, se puede desarrollar una noción de justicia que, por su propio fundamento solidario, induzca a crear una responsabilidad colectiva que busque como fin ultimo la integración social, desde la equidad y la justicia que debe prevalecer en las instituciones sociales, como proceso irreductible de acciones ciudadanas coordinadas desde la institucionalidad, como racionalidad política. Sólo una racionalidad política basada en juicios morales podrá fortalecer un proceso de institución ciudadana como proyecto de transformación e integración social.

La autorreflexión como evolución moral, producto de un orden institucional con niveles de inequidad e injusticia alarmantes, nos permite cuestionar el status quo con miras a crear un marco normativo que regule la interacción social, desde el res- 


\section{Zulay Díaz Montiel}

peto a las diferencias y a la dignidad, como derechos humanos fundamentales. La importancia de esto, es el interés emancipatorio que pueda despertar en la sociedad para superar la razón instrumental en la que están inmersas las instituciones políticas del Estado neoliberal; que rige la vida política de sujetos que apenas despiertan en su condición de ciudadanos para reinventar sus instituciones políticas como fuente de legitimación, enfrentando los problemas sociales en el espacio público. Una práctica política que se realiza en estas condiciones del mundo de vida de los seres sociales, entiende que solamente a partir de los principios de justicia y razones morales universales, se pueden ganar espacios de interacción para una democratización radical de los sistemas de representación, comunicación y dialogicidad del poder: como único camino hacia la integración ciudadana y social.

\section{Conclusiones}

La legitimación democrática del poder y las formas institucionales que le dan sentido es lo que caracteriza a un Estado de derecho. Es obvio que este Estado y todos sus sistemas de interacción e integración social, deben hacer tránsito por las relacio- nes sociales y políticas que se crean con la ciudadanía, base simbólica y discursiva de la política. Entonces, se puede observar que sería una consecuencia natural al interior y exterior de estas relaciones, las disputas y conflictos que pueden enfrentar ambos espacios en sus particulares desarrollos.

En este orden de ideas, las correspondencias entre esas relaciones no siempre pueden ser determinadas unívocamente, de acuerdo a un tipo hegemónico de interés particular o social, sobre uno u otros. Acá se trata de resolver relaciones que con respecto al Estado son estratégicamente entendidas coactivamente, $y$ con respecto a la ciudadanía, deben ser comunicativas y prácticamente, dirimirse y ser consensuadas de acuerdo al ejercicio de una racionalidad dialógica, pues en esta posición política es que radica la fuerza (coacción) argumentativa de la ciudadanía.

La justicia y el interés emancipador que la acompaña, deben permitir su concreción política. Eso sólo sería viable si la coordinación del poder comunicativo ciudadano logra abrirse a la institución de un espacio público de encuentro con el otro, donde se expongan los intereses que puedan ser generalizables a partir de razones morales y actos sociales. Estaríamos, en presencia de una justicia en su 
contenido fáctico de bien posible.

En este sentido, el mundo moral que nosotros debemos hacer realidad para que las instituciones del Estado respondan a este desafío, está en apuntalar los procesos pragmáticos de la racionalidad comunicativa, como la principal fuerza de discusión pública y de legitimación del Estado. Esto nos compromete a todos por igual, puesto que son las razones morales las únicas capaces de emanciparnos de las ideologías políticas que nos mantienen cosificados.

Deliberar acerca de la construcción de la racionalidad moral y la justicia social de las instituciones políticas pasa por: i) afianzar la autonomía como pueblos soberanos para defender los intereses que puedan ser generalizables desde una formación de la voluntad común. ii) democratizar el orden institucional desde la racionalidad político-moral y la justicia social de ciudadanos que reinventan la moralidad de sus instituciones políticas. iii) legitimar nuestra cultura política desde una razón práctico-moral que sólo podría ser intersubjetiva y radicalmente democrática. En fin, se trata de abrirnos a la posibilidad de creación de un nuevo orden social, que nos haga capaces de proponer dentro del contexto sociopolítico, la apertura hacia lo intersubjetivo y plural, y recuperar de ese modo la racionalidad moral de las instituciones. Es decir, debemos obrar políticamente según los intereses públicos de la mayoría ciudadana.

\section{Lista de Referencias}

BOLADERAS, Margarita

1996 Comunicación, ética y política, Habermas y sus críticos, España, Tecnos.

COHEN, Jean; ARATa, Andrew

2002 Sociedad civil y teoria politica. Mexico. Fondo de Cultura Económica.

CASTORIADIS, Cornelius

2001 Figuras de lo pensable. Argentina. Fondo de Cultura Económica.

DE ZAN, Julio

2002 Panorama de la etica continental contemporanea. España. Ediciones Akal.

HABERMAS, Jürgen

1998a Identidades nacionales y postnacionales. Espafta. Tecnos.

HABERMAS, Jürgen

1998b Mas alla del Estado nacional. Espana. Trotta.

HABERMAs, Jürgen

1996 La necesidad de revisi6n de la izquierda. Es. pana. Tecnos.

HABERMAS, Jürgen

1981 Escritos sobre moralidad y eticidad. España. Paidós.

HABERMAS, Jiirgen

2003 La etica del discurso y la cuesti6n de la verdad. Coloquio con Jiirgen Habermas. (Paris IV, Sorbona, 1 de fe- 
Luciano Bellinni Fedozzi, sdb.

brero de 2001). España. NINO, Carlos

Paidós.

1997 La constituci6n de la demo-

HABERMAS, Jürgen

2002 El futuro de la naturaleza humana. 1Hacia una eugenesia liberal? Espafta. Paidós.

HABERMAS, Jiirgen

1993 "Los usos pragmaticos, eticos y morales de la razón practica" en: Herrera, M. Jürgen Habermas: moralidad, ética y politica. Propuestas y criticas. Mexico. Alianza Editorial. cracia deliberativa. España. Gedisa.

PRADOS, Alfredo

1999 Ethos y polis. Bases para una reconstrucción de la filosofia política. España. Ediciones Universidad de Navarra. Colección filosófica Num. 152. Facultad de Filosofía y Letras. 